\title{
Molecular composition distribution of polycarbonate/ polystyrene blends in cylindrical nanopores
}

\author{
Hui $\mathrm{Wu}^{1}$, Zhaohui $\mathrm{Su}^{2}$ and Atsushi Takahara ${ }^{1}$ \\ Polycarbonate/polystyrene (PC/PS) blend nanorods with various diameters were prepared by melt-wetting porous anodic \\ aluminum oxide templates with partially miscible blend melts. The molecular composition distribution of PC/PS blend polymers \\ inside nanoporous templates of varying diameters was investigated by scanning electron microscopy, Fourier transform infrared \\ and differential scanning calorimetry. A gradient composition distribution of the polymer blends formed in the nanopores owing \\ to the difference in viscosity between the two polymers during capillary flow. The PC content of the nanorods increased from \\ top to bottom along the long axis of the rods but decreased with rod diameter owing to stronger confinement by the nanopores. \\ Polymer Journal (2011) 43, 600-605; doi:10.1038/pj.2011.25; published online 20 April 2011
}

Keywords: AAO; molecular composition distribution; nanorods; polymer blends

\section{INTRODUCTION}

The structure and morphology of polymers under cylindrical confinement have attracted considerable interest recently. ${ }^{1}$ Attention has been focused on structure formation processes such as chain dynamics, ${ }^{2-5}$ crystallization $^{5-19}$ and phase separation ${ }^{20-28}$ under the influence of the two-dimensional confinement imposed by cylinder geometry and interfacial interactions with pore walls. Owing to the special shape of nanocylinders with high aspect ratios (length to diameter), the fabricated nanomaterials have unusual mechanical, chemical, optical and electronic properties, as well as specific surface properties. ${ }^{1}$ For amorphous polystyrene (PS) confined in cylindrical alumina nanopores, an unexpected enhancement of flow and a reduction in intermolecular entanglement have been observed, leading to higher mobility of polymer in the confined geometry than that of unconfined chains. ${ }^{2}$ In the case of semicrystalline polymers under nanocylindrical geometry, the polymers exhibit novel orientation, ${ }^{5-17}$ polymorphism ${ }^{18}$ and segmental dynamic behavior. ${ }^{5,17}$ The crystals that form in nanorods at low supercooling show perpendicular orientation; that is, the $c$-axes of the polymer crystals that develop in cylindrical nanopores preferentially orient perpendicular to the long axis of the nanopore. ${ }^{5-17}$ The crystallinities ${ }^{8-10}$ and melting temperatures $^{10,17}$ of nanorods are reduced compared with those of bulk polymer, owing to the spatial confinement of the nanopores. Strong deviation from the normal relaxation behavior of poly(vinylidene fluoride) was observed inside nanopores. The dynamic and semicrystalline structure of the polymer at the nanometer level was explained by spatial confinement and interfacial interactions. ${ }^{5}$

Amorphous block copolymers (BCPs) confined in nanopores exhibit novel morphologies in simulations ${ }^{20-23}$ and experiments ${ }^{24-27}$ that are not apparent in the bulk form. A variety of self-assembled structures, such as concentric lamellae, core-shell cylinders, stacked disks, toroids and helices, are formed within the nanorods of phaseseparating $\mathrm{BCPs}$ owing to the interactions between the blocks and the walls, the curvature forced onto the $\mathrm{BCP}$ morphology, and the commensurability between the pore diameter and the natural period of the BCP morphology in bulk. For poly(methyl methacrylate)/ polystyrene nanotubes prepared by solution-wetting nanopores, the morphology of the blends was dependent on annealing time because of Rayleigh instabilities and phase separation. ${ }^{28}$

Several polymer blends yield high-performance materials with combinations of properties unattainable in any single polymer component. ${ }^{29}$ For example, polycarbonate/polystyrene (PC/PS) blends are known to be partially miscible, ${ }^{30-32}$ and their morphology and properties have been well studied. ${ }^{31-36}$ These polymer pairs exhibit excellent flame retardancy and high fluidity, critical for the development of environmentally friendly materials and thin-wall applications for packaging of electronic goods. Therefore, it is crucial to understand the effects of the confinement of nanopores on the morphology and properties of polymer blends to develop novel polymer blend nanomaterials and nanodevices. In the previous works, the authors studied completely miscible polystyrene/poly(vinyl methyl ether) blends in ultrathin films $s^{37,38}$ and poly(2,6-dimethylphenylene oxide)/ polystyrene blends in nanopores. ${ }^{39}$ Phase-separated structures quite different from the bulk were reported. In the present work, in order to explore the molecular composition distribution of partially miscible polymer blends under the confinement of nanocylinders, PC/PS blend nanorods with various diameters were prepared by meltwetting porous anodic aluminum oxide (AAO) templates and the

${ }^{1}$ Institute for Materials Chemistry and Engineering, Kyushu University, Fukuoka, Japan and ${ }^{2}$ State Key Laboratory of Polymer Physics and Chemistry, Changchun Institute of Applied Chemistry, Chinese Academy of Sciences, Jilin, PR China

Correspondence: Professor A Takahara, Institute for Materials Chemistry and Engineering, Kyushu University, 744 Motooka, Nishi-ku, Fukuoka 819-0395, Japan.

E-mail: takahara@cstf.kyushu-u.ac.jp

Received 12 December 2010; revised 22 February 2011; accepted 25 February 2011; published online 20 April 2011 
morphology of polymer blends in cylindrical nanopores were studied. A gradient composition distribution of partially miscible polymer blend nanorods is demonstrated.

\section{EXPERIMENTAL PROCEDURE}

\section{Materials}

Poly(bisphenol A carbonate) (PC; $M_{\mathrm{n}}=24600, M_{\mathrm{w}} / M_{\mathrm{n}}=1.88$; Sigma-Aldrich, Co., St Louis, MO, USA $)$ and atactic PS $\left(M_{\mathrm{n}}=115000, M_{\mathrm{w}} / M_{\mathrm{n}}=1.04\right.$; Polymer Source Inc., Dorval (Montreal), QC, Canada) were used as received. Blend films of PC/PS were prepared by solution casting from $\mathrm{CHCl}_{3}$ into a Petri dish. The weight fraction of PC in the mixtures was 0.50 . After most of the solvent had evaporated, the cast film was further dried under vacuum at $70{ }^{\circ} \mathrm{C}$ for $36 \mathrm{~h}$ to remove any residual solvent. Afterward, for the preparation of polymer blend nanorods, $200-\mu \mathrm{m}$ thick PC/PS blend films were obtained by compression molding the cast PC/PS films between sheets of aluminum foil under vacuum at $250{ }^{\circ} \mathrm{C}$ for $4 \mathrm{~min}$ and quickly quenching the films in ice water.

AAO templates with depth of $140 \mu \mathrm{m}$ and pore diameters of 300, 65 and $35 \mathrm{~nm}$ (Figures 1a-c) were prepared through a two-step anodization process. The depth and pore diameters were controlled by adjusting the anodization conditions (type of electrolyte, applied voltage, anodization time and porewidening time). Details on the anodization process are described elsewhere. ${ }^{40,41}$

\section{Preparation of PC/PS blend nanorods}

$\mathrm{PC} / \mathrm{PS}$ blend nanorods were prepared by drawing polymer blend melts into the AAO nanopores through capillary force. Porous AAO templates were placed on top of compression-molded PC/PS blend films. Each assembly was annealed at $250{ }^{\circ} \mathrm{C}$ under vacuum and then quickly quenched in ice water. The temperature of $250^{\circ} \mathrm{C}$ was deliberately chosen to yield a higher rate of polymer capillary rise into the nanopores, to be cool enough for polycarbonate and to limit degradation of the PS, the same conditions used for extrusion blending of PC/PS. ${ }^{34}$ To obtain nanorods of $\sim 90 \mu \mathrm{m}$ in length for Fourier transform infrared (FTIR) measurement, the 300- and 65-nm diameter nanorods were annealed for $3 \mathrm{~h}$, and the $35-\mathrm{nm}$ diameter nanorods were annealed for $5 \mathrm{~h}$. A schematic diagram of the sample preparation is shown in Figure 2. After annealing the bulk films at $250{ }^{\circ} \mathrm{C}$ for $5 \mathrm{~h}$, no structural changes were detected by thermogravimetric analysis, gel permeation chromatography and FTIR.

\section{Characterization}

The morphologies of the AAO templates and PC/PS nanorods were investigated using an S-4300SE (Hitachi High-Technologies Corporation, Tokyo, Japan) scanning electron microscope (SEM) at an acceleration voltage of $5 \mathrm{kV}$. A thin layer of osmium was coated onto the sample surface before SEM observation.
Micro-FTIR spectroscopy of the polymer blend compositions at different positions in the nanorods and attached bulk films were performed using a PerkinElmer Spectrum One FTIR Spectrometer (PerkinElmer Instruments, Norwalk, CT, USA) in connection with an Autoimage microscope equipped with a mercury-cadmium telluride detector operating in transmission mode. The operation of the microscope and collection of optical images and spectra from the sample were controlled by the Autoimage software (Perkin-Elmer Japan Company, Osaka, Japan). To prepare the PC/PS nanorods for FTIR measurement, the combined template/polymer assemblies were immersed in $5 \mathrm{wt} \%$ phosphoric acid solution for $36 \mathrm{~h}$ to remove the inorganic AAO templates, leaving arrays of $\mathrm{PC} / \mathrm{PS}$ nanorods protruding from the PC/PS films. Thin slices of the cross-section from each PC/PS film with protruding nanorods were cut using a razor blade after removal of the AAO templates. During the micro-FTIR measurements, the aperture size was $300 \times 30 \mu \mathrm{m}^{2}$ and the resolution along the long axis of the rod was $30 \mu \mathrm{m}$. The spectra were collected at $2-\mathrm{cm}^{-1}$ resolution with 128 scans co-added. At least three replicate samples were prepared for FTIR analyses.

The absolute PC content in the PC/PS blend nanorods/film was calculated from the following equation:

$$
C_{\mathrm{PC}}=\frac{A_{888}}{A_{888}+4.47 A_{906}}
$$

where $C_{\mathrm{PC}}$ represents the content of PC in the PC/PS blends, $A_{888}$ and $A_{906}$ are the respective band areas for peaks at 888 and $906 \mathrm{~cm}^{-1}$ in FTIR spectra and 4.47 is the ratio of absorptive coefficients of the peak at $888 \mathrm{~cm}^{-1}$ to the peak at $906 \mathrm{~cm}^{-1}$ (see Supplementary Information for further detail).

Differential scanning calorimetry (DSC) thermograms were recorded on a PerkinElmer DSC (Perkin Elmer). Before each measurement, the bulk film attached to the nanorods was carefully, mechanically removed by using a sharp blade, and each porous alumina disk, with the PC/PS nanorods embedded in its nanopores, was dried at $70{ }^{\circ} \mathrm{C}$ for $36 \mathrm{~h}$ under vacuum. Stacked alumina disks were placed in aluminum pans and scanned from 30 to $250^{\circ} \mathrm{C}$ at a rate of $20{ }^{\circ} \mathrm{C} \mathrm{min}^{-1}$ under nitrogen $\left(30 \mathrm{ml} \mathrm{min}^{-1}\right.$ gas flow rate). The glass transition temperatures $\left(T_{\mathrm{g}}\right)$ of all samples were confirmed by examining the first derivatives of the DSC curves.

\section{RESULTS AND DISCUSSION}

The polymer blend nanorods were prepared by infiltrating porous AAO templates with partially miscible blend melts at $250^{\circ} \mathrm{C}$. AAO membranes, owing to their aligned, rigid and separated cylindrical pores, are ideal templates for the preparation of polymer nanomaterials with monodisperse diameters in the nanometer to micrometer scales. With respect to surface energies, inorganic materials such
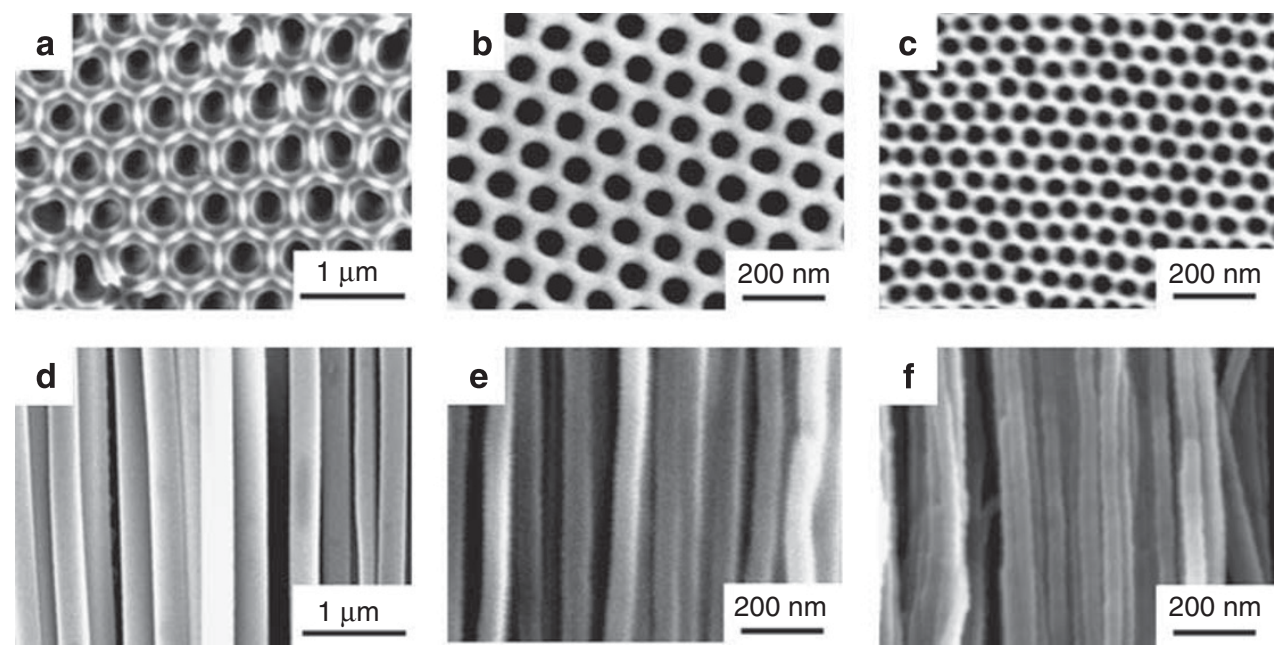

Figure 1 Scanning electron micrographs of anodic aluminum oxide templates with diameters of (a) $300 \mathrm{~nm}$, (b) $65 \mathrm{~nm}$ and (c) $35 \mathrm{~nm}$, and polycarbonate/ polystyrene nanorods with diameters of (d) $300 \mathrm{~nm}$, (e) $65 \mathrm{~nm}$ and (f) $35 \mathrm{~nm}$. 


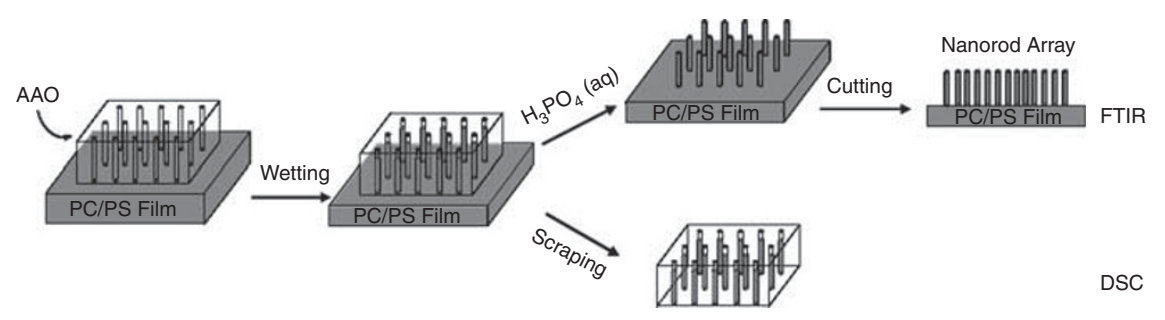

Figure 2 Schematic of sample preparation. FTIR, Fourier transform infrared; PC/PS, polycarbonate/polystyrene.
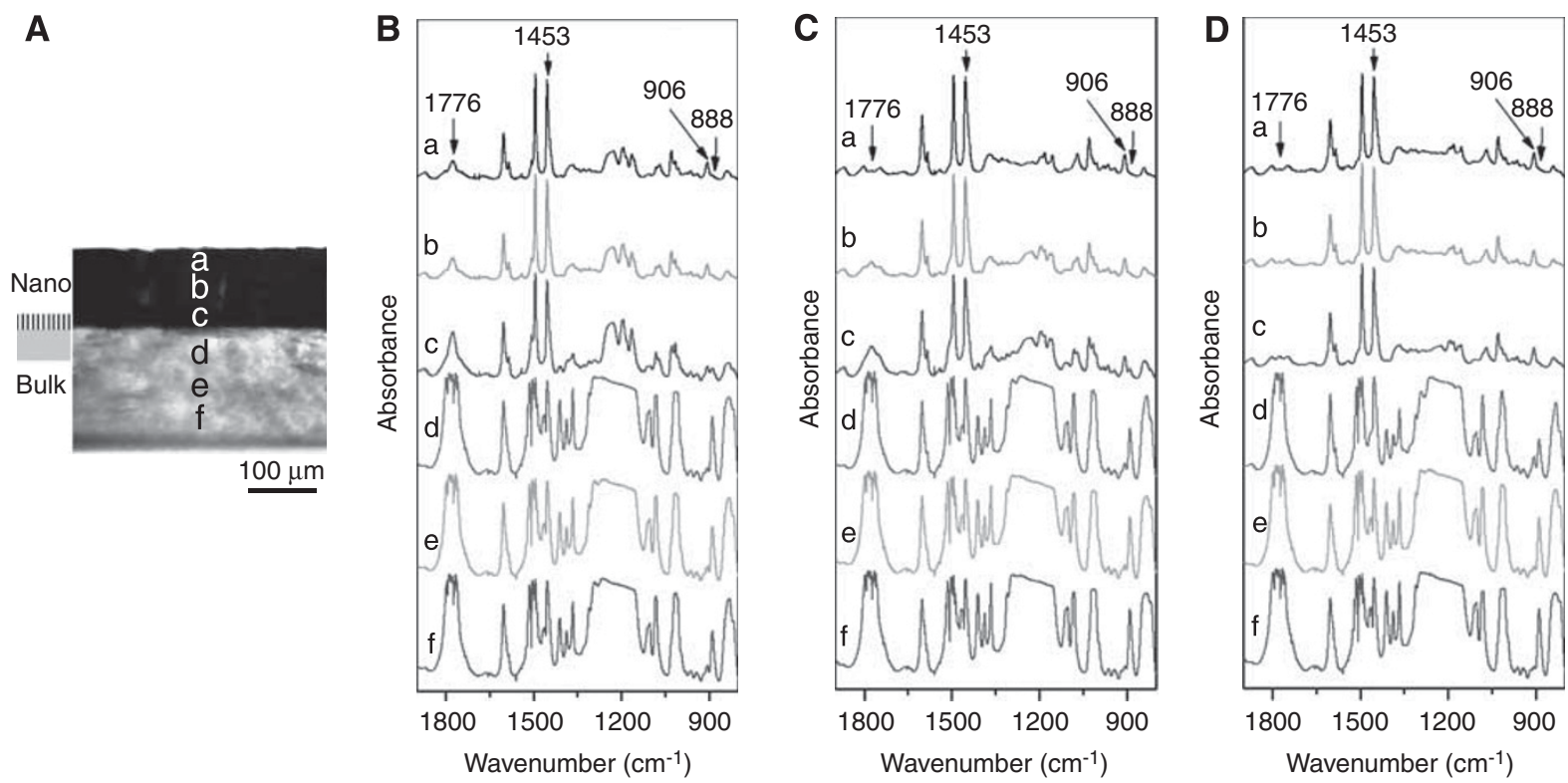

Figure 3 (A) Representative optical micrograph of a thin slice of polycarbonate/polystyrene nanorods/film prepared using an anodic aluminum oxide template with 65-nm diameter pores. The darker section on the top is the nanorod array. On the left is a schematic of the nanorods connected to the bulk film. (B-D) The corresponding micro-Fourier transform infrared spectra of nanorods with diameters of 300,65 and $35 \mathrm{~nm}$ at the respective measured positions. The spatial resolution at each position is $300 \times 30 \mu \mathrm{m}^{2}$ and the peak intensities are normalized to the $1453 \mathrm{~cm}^{-1}$ band.

as AAO templates are considered to be high-surface-energy materials $\left(\sim 350 \mathrm{mN} \mathrm{m}^{-1}\right)$, whereas most polymers are referred to as low-energy materials. For example, the surface free energies of PC and PS at $250{ }^{\circ} \mathrm{C}$ are $\sim 25$ and $24 \mathrm{mN} \mathrm{m}^{-1}$, respectively (http://www.surfacetension.de/solid-surface-energy.htm). Therefore, the low-energy PC and PS melts can wet the high-energy nanopore surfaces easily. Wetting of the pore walls by polymer melts causes a capillary rise of the melts into the nanopores, leading to the formation of polymer nanorods. ${ }^{8}$ Figures $1 \mathrm{~d}-\mathrm{f}$ show SEM images of PC/PS blend nanorods with diameters of 300,65 and $35 \mathrm{~nm}$ prepared by infiltrating AAO templates (Figures $1 \mathrm{a}-\mathrm{c}$ ) with $\mathrm{PC} / \mathrm{PS}$ blend melts, respectively. Transmission electron microscopy (TEM) results also confirmed that the generated nanomaterials had a solid structure at their center (data not shown).

Figure $3 \mathrm{~A}$ is a representative optical micrograph of a thin slice of the $\mathrm{PC} / \mathrm{PS}$ nanorods/film prepared using an AAO template with $65-\mathrm{nm}$ diameter pores. The area on the top is the nanorod array attached to a bulk film after removal of the AAO template, and it appears darker because of the scattering of light at the numerous nanorod/air interfaces, whereas the translucent section at the bottom is the cross-section of the residual PC/PS film. ${ }^{8}$ On the left in Figure $3 \mathrm{~A}$ is a schematic of the nanorods connected to the bulk film.

The PC/PS compositions in polymer blend nanorods/film were analyzed by micro-FTIR because micro-FTIR provides a simple and powerful approach for local analysis yielding high spatial resolution information with the advantages of both non-destructive and fast measurement. The microscope connected to the FTIR includes a viewing system that magnifies the visible-light image of the sample so that a point of interest in the sample can be seen, positioned and analyzed. The optical image of the sample was displayed in the monitor-visible window on the computer monitor. The map, operation of the microscope and spectra to be collected from the sample were controlled using the Autoimage software. The length of the nanorods was $\sim 90 \mu \mathrm{m}$. A spatial resolution of $300 \times 30 \mu \mathrm{m}^{2}$ was used during the measurement, and the resolution along the long axis of the rods, for obtaining spectra from the top to the bottom in a thin slice, was $30 \mu \mathrm{m}$. Figure $3 \mathrm{~B}$ shows the corresponding micro-FTIR spectra of 300-nm diameter nanorods in the measured positions. The top three curves are the spectra of nanorods in positions $a, b$ and $c$, whereas the bottom three curves represent the residual bulk film in positions $d, e$ and $f$, respectively. In the FTIR spectra of the PC/PS blends, ${ }^{42}$ the peak at $1776 \mathrm{~cm}^{-1}$ is the carbonyl stretching of the carbonate functional group of $\mathrm{PC},{ }^{43}$ at $888 \mathrm{~cm}^{-1}$ the $\mathrm{C}-\mathrm{CH}_{3}$ stretching of $\mathrm{PC},{ }^{43}$ at $1453 \mathrm{~cm}^{-1}$ the $\mathrm{CH}_{2}$ bending vibration of $\mathrm{PS}^{44}$ and at $906 \mathrm{~cm}^{-1}$ the characteristic out-of-plane vibration of the benzene ring of PS. ${ }^{44}$ It should be mentioned that the absorption peaks in the nanorod region are weaker than that in the bulk region, as the nanorods do not occupy the whole volume of the sample after removal of the AAO template. 
Table 1 Comparison of PC content at different positions in PC/PS blend nanorods/film

\begin{tabular}{|c|c|c|c|c|c|c|}
\hline \multirow[b]{2}{*}{$\begin{array}{l}\text { Rod } \\
\text { diameters }\end{array}$} & \multicolumn{3}{|c|}{ Nanorods (\%) } & \multicolumn{3}{|c|}{ Bulk (\%) } \\
\hline & $\begin{array}{c}\text { Position } \\
a\end{array}$ & $\begin{array}{c}\text { Position } \\
b\end{array}$ & $\begin{array}{c}\text { Position } \\
c\end{array}$ & $\begin{array}{c}\text { Position } \\
d\end{array}$ & $\begin{array}{c}\text { Position } \\
e\end{array}$ & $\begin{array}{c}\text { Position } \\
f\end{array}$ \\
\hline $300 \mathrm{~nm}$ & 3.1 & 5.4 & 16.1 & 63.5 & 55.9 & 52.5 \\
\hline $65 \mathrm{~nm}$ & 1.6 & 2.8 & 11.0 & 53.3 & 58.9 & 68.0 \\
\hline $35 \mathrm{~nm}$ & 1.6 & 1.7 & 3.7 & 33.0 & 67.3 & 68.2 \\
\hline
\end{tabular}

Abbreviation: PC/PS, polycarbonate/polystyrene.

To conduct a qualitative analysis across different positions in a sample, the band intensities (peak height) for all the data sets were normalized to that of the $1453 \mathrm{~cm}^{-1}$ band of PS. When the spectra of the $300-\mathrm{nm}$ diameter nanorods (Figure $3 \mathrm{~B}$ ) were examined using PS as reference, the relative intensity of the $1776-$ and $888-\mathrm{cm}^{-1}$ bands became enhanced from position $a$ to position $c$, suggesting that the PC content in the nanorods increased from top to bottom and a composition gradient formed along the long axis of rods. Similar results were observed in nanorods with diameters of 65 (Figure 3C) and $35 \mathrm{~nm}$ (Figure 3D), showing that a gradient composition distribution also formed in the smaller nanorods.

The relative intensities of the 1776 and $888 \mathrm{~cm}^{-1}$ peaks at position $c$ in $65-\mathrm{nm}$ diameter PC/PS blend nanorods were weaker than that at position $c$ in 300-nm diameter nanorods. Reduced intensities at positions $b$ and $a$ could also be seen in 65-nm nanorods compared with those in 300-nm nanorods. This suggests that the overall PC content in the $65-\mathrm{nm}$ diameter nanorods was less than that in the $300-\mathrm{nm}$ diameter nanorods. For nanorods with diameters as small as $35 \mathrm{~nm}$, the intensities at positions $a, b$ and $c$ were also less than those at corresponding positions in the 65- and 300-nm diameter nanorods, revealing the trend that $\mathrm{PC}$ content in nanorods decreases as rod diameter decreases.

The PC content at different positions in the nanorods/film was quantified from the intensities of the peaks at 888 and $906 \mathrm{~cm}^{-1}$ using Equation (1). Table 1 lists the PC contents for both the nanorods and the bulk films at different positions extracted from the FTIR data. The PC content in the 300-nm diameter nanorods at positions $a, b$ and $c$ was $3.1,5.4$ and $16.1 \%$, respectively. This clearly shows that its content in nanorods increased from the top (position a) to the bottom (position $c$ ), which was also observed in the 65- and 35-nm diameter nanorods. Although the PC content in the original PC/PS film was $\sim 50 \%$, the PC content in $35-\mathrm{nm}$ diameter nanorods was $<4 \%$, indicating that the smaller nanorods were mainly composed of the PS component. The higher PS content in the nanorods compared with the bulk reflects that the PS component preferentially occupied the nanopores. The PC content of the 35-nm diameter nanorods was much lower than that of the 65- and 300-nm diameter nanorods, showing that PC content decreases as pore diameter decreases, and that the degree of confinement imposed by the nanopores strongly influences the molecular composition distribution of polymer blends in the resulting nanorods.

DSC is one of the most frequently used methods for assessing polymer-polymer miscibility, specifically by measuring the glass transition temperature $\left(T_{\mathrm{g}}\right)$. Miscible polymer blends exhibit a single $T_{\mathrm{g}}$ between the $T_{\mathrm{g}}$ 's of the individual components, whereas for partially miscible systems the $T_{\mathrm{g}}$ 's approach each other but do not become identical. ${ }^{32}$ Figure 4 shows the DSC curves of the PC/PS blends in 300-, 65- and 35-nm diameter nanorods in bulk film, in

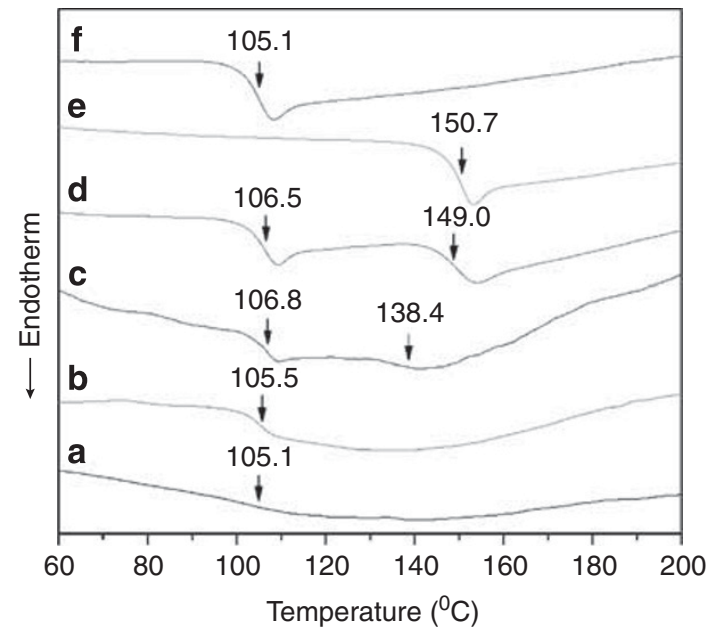

Figure 4 Differential scanning calorimetry thermograms of the polycarbonate/polystyrene (PC/PS) blends in (a) 35-nm diameter nanorods, (b) 65-nm diameter nanorods, (c) 300-nm diameter nanorods, (d) bulk film, (e) pure PC and (f) pure PS.

pure PC and pure PS, for reference. A thermogram of an empty AAO template was featureless, ${ }^{17}$ whereas the $T_{\mathrm{g}}$ 's of pure PC and pure PS were 150.7 and $105.1{ }^{\circ} \mathrm{C}$, respectively. On the PC/PS bulk film curve (Figure $4 \mathrm{~d}$ ), the transition at $149.0^{\circ} \mathrm{C}$ corresponds to the $T_{\mathrm{g}}$ of the PC-rich phase, and the transition at $106.5^{\circ} \mathrm{C}$ is the contribution of the PS-rich phase. The slight shift of the two $T_{\mathrm{g}}$ 's in the scan shows that PC/PS blends are partially miscible ${ }^{30-32}$ indicating that the bulk film has a heterogeneous two-phase structure and only a limited amount of each component is dissolved in the other phase. For the PC/PS blends that we used, the calculated critical Flory-Huggins interaction parameter $\left(\chi_{\mathrm{c}}\right)$ was $\sim 0.009,{ }^{30,31}$ whereas the Flory-Huggins interaction parameter at $250{ }^{\circ} \mathrm{C}$, $\chi$, was $0.038,{ }^{32}$ much higher than $\chi_{\mathrm{c}}$. This further corroborates the finding that PC/PS blends are partially miscible. ${ }^{30-32}$ On the DSC curve for 300-nm diameter nanorods (Figure 4c), the transition at $106.8^{\circ} \mathrm{C}$, which corresponds to the $T_{\mathrm{g}}$ of the PS-rich phase, appeared clearly. Another transition at $138.4^{\circ} \mathrm{C}$, associated with the $T_{\mathrm{g}}$ of the PC-rich phase, shifted to lower temperatures, and the relative magnitude of the heat change was much weaker than that in the bulk material. This indicates that phase separation also occurred for the PC/PS blends in the 300-nm diameter nanorods, and that the relative content of PC in those nanopores was lower than that in bulk. For the polymer blends inside the 65-nm nanopores, the transition of the PS-rich phase at $105.5^{\circ} \mathrm{C}$ could be observed, and the transition of the PC-rich phase at high temperatures was hard to distinguish, indicating that the PC content in the $65-\mathrm{nm}$ nanopores was lower than that in the 300-nm nanopores. Furthermore, in the 35-nm nanorods, only a weak transition located at $105.1{ }^{\circ} \mathrm{C}$ could be seen. The DSC results reveal that the PC content in the nanorods decreased as nanorod diameter decreased, which is in good agreement with the FTIR results.

When the polymer blends enter the nanopores during capillary flow, its molecular composition distribution is governed by the viscosity difference between the polymers, surface properties of the polymer blends and degree of confinement by the pore diameter. For PC/PS blends, the viscosity of PC at $250^{\circ} \mathrm{C}$ can reach $8380(\mathrm{Pas}),{ }^{45}$ whereas that of PS is only about 170 (Pas). ${ }^{46}$ Under the same conditions, the compositions with lower viscosity have higher mobility to enter into nanopores via capillary force. For the compression- 
molded bulk film annealed at $250{ }^{\circ} \mathrm{C}$, because of the partial miscibility of PC/PS, ${ }^{30-32}$ phase separation occurred and PC was more likely to aggregate to form PC-rich dots and strips (see Figure S4 in Supplementary Information). Thus, when the AAO/polymer assembly was annealed at $250^{\circ} \mathrm{C}$ to prepare the nanorods, phase segregation and the capillary flow of the melts into the nanopores took place in the bulk film simultaneously. Therefore, driven by capillary force, the PS-rich compositions with lower viscosity preferentially entered the nanopores, whereas the PC-rich compositions were more likely to stay in the bulk film because of its higher viscosity and lower mobility, causing the PS content in the nanopores to rise higher than that in bulk.

Furthermore, in considering the surface composition of the polymer blends, the lower-surface-free-energy component was enriched at the surface of the polymer blend film to minimize the surface free energy. ${ }^{37,38}$ At $250^{\circ} \mathrm{C}$, the surface free energy of PS is $\sim 24 \mathrm{~m} \mathrm{~m}^{-1}$, less than that of PC $\left(25 \mathrm{mN} \mathrm{m}^{-1}\right.$; http://www.surface-tension.de/solidsurface-energy.htm). Before annealing, the surface PS content of the compression-molded PC/PS film observed in X-ray photoelectron spectroscopy (XPS) was $\sim 24.7 \%$ (Figure S5 in Supplementary Information), showing that PC was enriched on the surface of the blend film owing to the stronger interaction between PC and aluminum foil during the compression process. After thermal annealing at $250{ }^{\circ} \mathrm{C}$ for $3 \mathrm{~h}$, the PS content on the surface of the blend film reached $92.5 \%$. The high content of PS on the surface means that the PS component covers the film surface easily owing to its lower surface energy and higher mobility. Therefore, the enrichment of PS on the surface during the annealing process facilitates the entry of PS-rich compositions into the nanopores compared with PC-rich compositions.

Within the nanopores during capillary flow, the low-viscosity PS component with its higher mobility moves upward, whereas the PC component with higher viscosity is left behind and leads to larger amounts of PC remaining at the bottom of the nanorods (position $c$ ), causing the weight fraction of PC at the bottom of the nanorods to be larger than that at the top (position $a$ ). Therefore, the difference in viscosity between PC and PS has a key role in determining the formation of a gradient composition distribution in PC/PS blend nanorods during capillary flow. It is reported that PS with low molecular weights wetted alumina nanopores at much higher rates than those with high molecular weights, ${ }^{3}$ showing that low-viscosity PS is enriched in nanopores, which is consistent with our results. For the polymers that we used, owing to the polydispersity (1.88) of the PC component, it is reasonable to deduce that the content of low molecular weight $\mathrm{PC}$ in nanopores is higher than that in bulk and that a gradient distribution of different molecular weight $\mathrm{PC}$ is also formed in the blend nanorods.

It is well known that when pore diameters are smaller a polymer melt requires more time to fill nanopores by capillary flow to yield nanorods of the same length as for larger diameter pores. ${ }^{25}$ Thus, the compositions, especially those with higher viscosity, should have a more difficult time entering smaller nanopores owing to their stronger spatial confinement. To achieve the highest capillary rise of polymers into nanopores, the template will select the polymers with lowest viscosity and highest mobility to enter the nanopores. In the optical micrographs of thin slices of PC/PS film after annealing (Supplementary Figure S4), the volume of PC-rich dots or strips can be seen to increase, indicating that PC content in the PS-rich region decreased and the degree of phase separation increased. Therefore, during the longer annealing time in the preparation of the smaller nanorods, phase separation develops, and the PS-rich compositions with lower PC content have a higher chance of entering the smaller nanopores, suggesting that the content of PC in smaller nanopores is less than that in larger ones.

\section{CONCLUSIONS}

PC/PS blend nanorods with diameters of 300,65 and $35 \mathrm{~nm}$ were prepared by melt-wetting nanopores with partially miscible PC/PS blend melts. The molecular composition distribution of PC/PS blends in cylindrical nanopores was studied by SEM, FTIR and DSC. As the polymer blends entered the nanopores by capillary force, the composition with lower viscosity showed higher mobility when entering the nanopores, leading to the formation of a gradient composition distribution in the resultant nanorods along the long axis direction of the rods. The PC weight fraction at the bottom of PC/PS nanorods was higher than that at the top. Across nanopores of varying diameter, the content of PC in smaller nanopores was less than that in larger ones owing to the stronger confinement of the nanopores. These results may help researchers better understand and control the morphology and properties of polymer blends during capillary flow under cylindrical confinement. As the FTIR and DSC analysis produce the averaged results of numerous nanorods across a rod array, more detailed studies of the morphology and phase behavior of PC/PS blends in a single nanorod will be conducted in the near future using TEM and nanothermal analysis (nano-TA).

\section{ACKNOWLEDGEMENTS}

This work was supported by a Grant-in-Aid for the Global COE Program 'Science for Future Molecular Systems' from the Ministry of Education, Culture, Science, Sports and Technology of Japan. Z.S. thanks the National Natural Science Foundation of China (20774097, 50921062) for support.

1 Steinhart, M. Supramolecular organization of polymeric materials in nanoporous hard templates. Adv. Polym. Sci. 220, 123-187 (2008).

2 Shin, K., Obukhov, S., Chen, J. T., Huh, J., Hwang, Y., Mok, S., Dobriyal, P. Thiyagarajan, P. \& Russell, T. P. Enhanced mobility of confined polymers. Nat. Mater. 6, 961-965 (2007).

3 Zhang, M. F., Dobriyal, P., Chen, J. T., Russell, T. P., Olmo, J. \& Merry, A. Wetting transition in cylindrical alumina nanopores with polymer melts. Nano Lett. 6, 1075-1079 (2006).

4 Serghei, A., Chen, D., Lee, D. H. \& Russell, T. P. Segmental dynamics of polymers during capillary flow into nanopores. Soft Matter 6, 1111-1113 (2010).

5 Martin, J., Mijangos, C., Sanz, A., Ezquerra, T. A. \& Nogales, A. Segmental dynamics of semicrystalline poly(vinylidene fluoride) nanorods. Macromolecules 42, 5395-5401 (2009).

6 Steinhart, M., Senz, S., Wehrspohn, R. B., Gösele, U. \& Wendorff, J. H. Curvaturedirected crystallization of poly(vinylidene difluoride) in nanotube walls. Macromolecules 36, 3646-3651 (2003).

7 Steinhart, M., Göring P., Dernaika, H., Prabhukaran, M., Gösele, U., Hempel, E. \& Thurn-Albrecht, T. Coherent kinetic control over crystal orientation in macroscopic ensembles of polymer nanorods and nanotubes. Phys. Rev. Lett. 97, 027801 (2006).

$8 \mathrm{Wu}$, H., Wang, W., Yang, H. \& Su, Z. Crystallization and orientation of syndiotactic polystyrene in nanorods. Macromolecules 40, 4244-4249 (2007).

9 Wu, H., Wang, W., Huang, Y. \& Su, Z. Orientation of syndiotactic polystyrene crystallized in cylindrical nanopores. Macromol. Rapid Commun. 30, 194-198 (2009).

10 Shin, K., Woo, E., Jeong, Y. G., Kim, C., Huh, J. \& Kim, K. W. Crystalline structures, melting, and crystallization of linear polyethylene in cylindrical nanopores. Macromolecules 40, 6617-6623 (2007).

11 Liu, Y., Cui, L., Guan, F. X., Gao, Y., Hedin, N. E., Zhu, L. \& Fong, H. Crystalline morphology and polymorphic phase transitions in electrospun nylon-6 nanofibers. Macromolecules 40, 6283-6290 (2007).

$12 \mathrm{Ma}$, Y., Hu, W. B., Hobbs, J. \& Reiter, G. Understanding crystal orientation in quasi-onedimensional polymer systems. Soft Matter 4, 540-543 (2008).

13 Huang, P., Zhu, L., Cheng, S. Z. D., Ge, Q., Quirk, R. P., Thomas, E. L., Lotz, B., Hsiao, B. S., Liu, L. Z. \& Yeh, F. J. Crystal orientation changes in two-dimensionally confined nanocylinders in a poly(ethylene oxide)-b-polystyrene/polystyrene blend. Macromolecules 34, 6649-6657 (2001).

14 Nojima, S., Ohguma, Y., Kadena, K., Ishizone, T., Iwasaki, Y. \& Yamaguchi, K. Crystal orientation of poly( $\varepsilon$-caprolactone) homopolymers confined in cylindrical nanodomains. Macromolecules 43, 3916-3923 (2010).

15 Chung, T. M., Wang, T. C., Ho, R. M., Sun, Y. S. \& Ko, B. T. Polymeric crystallization under nanoscale 2D spatial confinement. Macromolecules 43, 6237-6240 (2010). 
16 Garcia-Gutierrez, M. C., Linares, A., Hernandez, J. J., Rueda, D. R., Ezquerra, T. A., Poza, P. \& Davies, R. J. Confinement-induced one-dimensional ferroelectric polymer arrays. Nano Lett. 10, 1472-1476 (2010).

17 Lutkenhaus, J. L., McEnnis, K., Serghei, A. \& Russell, T. P. Confinement effects on crystallization and Curie transitions of poly(vinylidene fluoride-co-trifluoroethylene). Macromolecules 43, 3844-3850 (2010).

18 Wu, H., Wang, W., Huang, Y., Wang, C. \& Su, Z. Polymorphic behavior of syndiotactic polystyrene crystallized in cylindrical nanopores. Macromolecules 41, 7755-7758 (2008).

19 Woo, E., Huh, J., Jeong, Y. G. \& Shin, K. From homogeneous to heterogeneous nucleation of chain molecules under nanoscopic cylindrical confinement. Phys. Rev. Lett. 98, 136103 (2007).

$20 \mathrm{He}$, X. H., Song, M., Liang, H. J. \& Pan, C. Y. Self-assembly of the symmetric diblock copolymer in a confined state: Monte Carlo simulation. J. Chem. Phys. 114, 10510-10513 (2001).

$21 \mathrm{Li}$, W. H., Wickham, R. A. \& Garbary, R. A. Phase diagram for a diblock copolymer melt under cylindrical confinement. Macromolecules 39, 806-811 (2006).

22 Zhu, Y. T. \& Jiang, W. Self-assembly of diblock copolymer mixtures in confined states: a Monte Carlo study. Macromolecules 40, 2872-2881 (2007).

23 Yu, B., Jin, Q. H., Ding, D. T., Li, B. H. \& Shi, A. C. Confinement-induced morphologies of cylinder-forming asymmetric diblock copolymers. Macromolecules 41, 4042-4054 (2008).

24 Shin, K., Xiang, H. Q., Moon, S. I., Kim, T., McCarthy, T. J. \& Russell, T. P. Curving and frustrating flatland. Science 306, 76 (2004).

25 Xiang, H. Q., Shin, K., Kim, T., Moon, S. I., McCarthy, T. J. \& Russell, T. P. Block copolymers under cylindrical confinement. Macromolecules 37, 5660-5664 (2004).

26 Sun, Y. M., Steinhart, M., Zschech, D., Adhikari, R., Michler, G. H. \& Gösele, U. Diameter-dependence of the morphology of PS-b-PMMA nanorods confined within ordered porous alumina templates. Macromol. Rapid Commun. 26, 369-375 (2005).

27 Dobriyal, P., Xiang, H., Kazuyuki, M., Chen, J.- T., Jinnai, H. \& Russell, T. P. Cylindrically confined diblock copolymers. Macromolecules 42, 9082-9088 (2009).

28 Chen, D., Chen, J. T., Glogowski, E., Emrick, T. \& Russell, T. P. Thin film instabilities in blends under cylindrical confinement. Macromol. Rapid Commun. 30, 377-383 (2009).

29 Utracki, L. A. Polymer Alloys and Blends (Hanser Publ., New York, 1989).

30 Patterson, D. \& Robard, A. Thermodynamics of polymer compatibility. Macromolecules 11, 690-695 (1978).

31 Fekete, E., Foldes, E., Damsits, F. \& Pukanszky, B. Interaction-structure-property relationships in amorphous polymer blends. Polym. Bull. 44, 363-370 (2000).
32 Kim, W. N. \& Burns, C. M. Thermal-behavior, morphology, and the determination of the Flory-Huggins interaction parameter of polycarbonate polystyrene blends. J. Appl. Polym. Sci. 34, 945-967 (1987).

33 Kunori, T. \& Geil, P. H. Morphology-property relationships in polycarbonate-based blends. I. Modulus. J. Macromol. Sci. Phys. 18, 93-134 (1980).

34 Rudin, A. \& Brathwaite, N. E. Polycarbonate blends with polystyrene and polypropylene. Polym. Eng. Sci. 24, 1312-1318 (1984).

35 Cheng, T. W., Keskkula, H. \& Paul, D. R. Property and morphology relationships for ternary blends of polycarbonate, brittle polymers and an impact modifier. Polymer 33, 1606-1619 (1992).

36 Chuai, C. Z., Almdal, K., Johannsen, I. \& Lyngaae-Jorgensen, J. Morphology evolution of polycarbonate-polystyrene blends during compounding. Polymer 42, 8217-8223 (2001).

37 Tanaka, K., Yoon, J. S., Takahara, A. \& Kajiyama, T. Ultrathinning-induced surface phase-separation of polystyrene poly(vinyl methyl-ether) blend film. Macromolecules 28, 934-938 (1995).

38 Takahara, A., Nakamura, K., Tanaka, K. \& Kajiyama, T. Surface aggregation structure and surface mechanical properties of binary polymer blend thin films. Macromol. Symp. 159, 89-96 (2000).

$39 \mathrm{Wu}$, H., Su, Z. \& Takahara, A. Gradient composition distribution in poly(2,6-dimethylphenylene oxide)/polystyrene blend nanorods. Soft Matter 7, 1868-1873 (2011).

40 Masuda, H. \& Fukuda, K. Ordered metal nanohole arrays made by a two-step replication of honeycomb structures of anodic alumina. Science 268, 1466-1468 (1995).

41 Li, A. P., Muller, F., Birner, A., Nielsch, K. \& Gösele, U. Hexagonal pore arrays with a $50-420 \mathrm{~nm}$ interpore distance formed by self-organization in anodic alumina. J. Appl. Phys. 84, 6023-6026 (1998).

42 Kong, X. M., Xie, X. M., Yang, R., Wang, K. H., Zhang, Z. M. \& Lei, H. Determination of the composition distribution of polymer blend films by using microscopic FTIR. Spectrosc. Spect. Anal. 20, 623-625 (2000).

43 Lee, S. N., Stolarski, V., Letton, A. \& Laane, J. Studies of bisphenol-A-polycarbonate aging by raman difference spectroscopy. J. Mol. Struct. 521, 19-23 (2000).

44 Liang, C. Y. \& Krimm, S. Infrared spectra of high polymers. VI. polystyrene. J. Polym. Sci. 27, 241-254 (1958).

45 Lomellini, P. Viscosity-temperature relationships of a polycarbonate melt: WilliamsLandel-Ferry versus Arrhenius behavior. Makromol. Chem. 193, 69-79 (1992).

46 Fox, T. G. \& Flory, P. J. The glass temperature and related properties of polystyrene. Influence of molecular weight. J. Polym. Sci. 14, 315-319 (1954).

Supplementary Information accompanies the paper on Polymer Journal website (http://www.nature.com/pj) 